\title{
EL COOPERATIVISMO DE TRABAJO Y SUS ORGANIZACIONES INTERMEDIAS. LA FEDERACIÓN COMO INSTANCIA DE COORDINACIÓN SECTORIAL EN LA CIUDAD DE SANTA FE, ARGENTINA ${ }^{1}$
}

\author{
Maricel Lorena Massera* \\ Luisina Logiodice ${ }^{\star *}$
}

\begin{abstract}
Resumen. En un contexto de importante crecimiento del cooperativismo de trabajo ocurrido principalmente desde la década de los noventa y profundizado a partir del 2000 , las organizaciones de segundo grado que nuclean a dichas cooperativas han cobrado impulso como mecanismos de promoción del sector. Partiendo de la descripción de estos procesos, y reconociendo las potencialidades que las organizaciones intercooperativas presentan tanto hacia el interior del sector como para con la sociedad, en este artículo se busca reflexionar y analizar un caso particular de reciente constitución, una federación de cooperativas de trabajo de la ciudad Santa Fe, Argentina. Para ello, se indaga en las motivaciones y necesidades que dieron origen a la federación, y el modo en que se intenta responder a ellas a partir de los objetivos y acciones que se plantean, además de caracterizar a los actores que la conforman y los vínculos que se establecen entre ellos, así como con otros actores institucionales. Finalmente, se procura reconocer las potencialidades que se presentan para el sector cooperativo de la región, a la vez de reflexionar acerca de la complejidad intrínseca de las experiencias de trabajo asociativo mercantil y de la integración intercooperativa en el desarrollo de objetivos comunes.
\end{abstract}

Palabras Clave: Cooperativismo de trabajo; Organizaciones de segundo grado; Integración intercooperativa.

\footnotetext{
* Instituto de Humanidades y Ciencias Sociales del Litoral (Universidad Nacional del Litoral (UNL), Argentina y Consejo Nacional de Investigaciones Científicas y Técnicas (CONICET), Argentina.

Contacto: massera.maricel@gmail.com

** Instituto de Humanidades y Ciencias Sociales del Litoral (Universidad Nacional del Litoral (UNL), Argentina y Consejo Nacional de Investigaciones Científicas y Técnicas (CONICET), Argentina.

Contacto: luisinalogiodice@gmail.com
}

1 Este trabajo forma parte del CAI+D 2016 "Trabajo y acumulación de capital: transformaciones recientes de las actividades productivas en el territorio de la provincia de Santa Fe", y del CAI+D Orientado 2017 "Repensando las políticas públicas de financiamiento a la Economía Social y Solidaria. Ampliando la mirada acerca de las lógicas de evaluación", ambos financiados por la Universidad Nacional del Litoral, Argentina. Una versión preliminar de este artículo fue presentada en el $13^{\circ}$ Congreso Nacional de Estudios del Trabajo, Buenos Aires, Argentina. 


\title{
WORKERS' COOPERATIVES AND ITS INTERMEDIARY ORGANIZATIONS. FEDERATION AS AN AGENCY OF MULTISECTORIAL COORDINATION IN THE CITY OF SANTA FE, ARGENTINA
}

\begin{abstract}
Within the framework of substantial growth of the workers' cooperative movement which took place chiefly in the ' 90 s and deepened at the beginning of the 21st century, second-tier organizations that syndicate such cooperatives have gained momentum as mechanisms that promote the sector. Beginning with the description of such processes and the acknowledgement of the potentialities that intercooperative organizations have for the sector itself and towards society, this article attempts to reflect and analyze a specific and recent case: a federation of workers' cooperatives established in the city of Santa Fe, Argentina. For that, it investigates the motivations and needs that gave rise to the federation and the means in which they are addressed in terms of the goals and actions proposed. In addition, this article characterizes their constituents and the links established between them, as well as other institutional agents. Finally, it recognizes the potentialities they present for the cooperative sector of the region, and reflect about the intrinsic complexity of associative work experiences and intercooperative integration in the development of common goals.
\end{abstract}

Keywords: Workers' Cooperativism; Second-tier Organizations; Intercooperative integration.

Original recibido el 12/07/2018

Aceptado para su publicación el 12/12/2018 


\section{Introducción}

El sector cooperativo se ha constituido desde sus orígenes como un actor relevante para el desarrollo social y económico en Argentina, y fue consolidándose a lo largo del siglo XX, con un particular impulso en la década de los noventa. Es en este momento en que estas organizaciones atraviesan un proceso de gran efervescencia -en especial el cooperativismo de trabajo- como alternativa para la superación de la crisis del empleo.

Ya en el período de posconvertibilidad, bajo un contexto de disminución en el nivel de desocupación, las cooperativas de trabajo continúan con un proceso de constante expansión, que fue acompañado por políticas públicas de promoción e impulso del sector. Ese proceso de crecimiento no sólo se observa en términos absolutos sino también en términos relativos, lo cual conlleva una reconfiguración del cooperativismo argentino (Acosta, Levin y Verbeke, 2013, pág. 32).

En particular, la provincia de Santa Fe ha estado vinculada tradicionalmente al desarrollo de mutuales y cooperativas, originadas en gran medida por la influencia de inmigrantes europeos que han poblado la zona agrícola-ganadera. Sin embargo, y en consonancia con lo ocurrido a nivel nacional, se observa durante las últimas décadas la importancia que han adquirido las cooperativas de trabajo en este territorio.

Es así que estas organizaciones se inscriben en lo que diversos autores denominan Economía Social (Chaves, 1999; Defourny, 2009), o Economía Social y Solidaria (Coraggio, 2011; Hintze, 2007), haciendo referencia a un sector ${ }^{2}$ que propone asegurar la base material de las personas y comunidades -integrado a una sociedad justa y equilibrada-, como así también a un proyecto de acción colectiva dirigido a contrarrestar las consecuencias negativas del capitalismo (Coraggio, 2011). Se trata de experiencias orientadas por principios autogestivos y solidarios, y que contemplan la autonomía de gestión, los procesos de decisión democrática y la primacía de las personas y del trabajo sobre el capital en la repartición de los beneficios (Defourny y Develtere, 2001).

Este auge del movimiento ha sido acompañado a su vez por diversas organizaciones que brindan apoyo al sector, muchas de las cuales han sido promovidas incluso desde las propias cooperativas mediante la conformación de instituciones de segundo grado que las nuclean. Es así que surge el interés del presente trabajo por analizar el proceso de reciente constitución de una federación de cooperativas de trabajo en la ciudad de Santa Fe, una organización que nuclea diez cooperativas de la zona dedicadas a diversas actividades, principalmente a la construcción. Entendiendo la importancia de profundizar acerca de los procesos de organización intercooperativos que procuran promover el desarrollo del sector, se propone en este trabajo reconocer las motivaciones y necesidades que le dieron origen, y el modo en que se intenta responder a ellas a partir de los objetivos y acciones que se plantean.

2 Éste estaría conformado por aquellas experiencias históricas del cooperativismo y el mutualismo, a las cuales se han sumado más recientemente otras iniciativas socioeconómicas como las empresas recuperadas, los emprendimientos socioproductivos, los clubes de truque y las empresas sociales, entre otras (Pastore, 2008). 
Al mismo tiempo, identificar los distintos actores que la conforman, caracterizar los vínculos que se establecen entre ellos así como con otros actores institucionales, de modo de comprender el proceso de gestación. Finalmente, reconocer en dicho marco las potencialidades que se presentan para el sector cooperativo de la región. El enfoque metodológico utilizado es de tipo cualitativo, combinando el análisis de fuentes documentales -tales como normativas y resoluciones- y de entrevistas semiestructuradas a miembros de la organización y a asesores externos a la misma. También se utilizó información secundaria, disponible en organismos públicos vinculados al sector.

\section{Impulso del sector cooperativo de trabajo. Contexto nacional y local}

Diversos autores analizan el proceso de evolución, crecimiento y reconfiguración del sector cooperativo en Argentina. Interesa aquí recuperar algunas características salientes que atañen al cooperativismo de trabajo en Argentina.

Siguiendo a Vuotto (2011, pág. 17) se puede reconocer que hasta mediados de los setenta el ritmo de creación de cooperativas de trabajo fue lento, pero posteriormente las dificultades estructurales en el mercado de trabajo revirtieron esta dinámica dando lugar a una expansión sostenida, que a partir del año 2000 alcanza niveles de crecimiento nunca antes vistos. Ya para la década de los noventa se identifica un significativo crecimiento de las cooperativas de trabajo: entre los años 1991 y 2000 se crearon 1.327 cooperativas $^{3}$ lo cual implica un crecimiento que casi triplica a las cooperativas creadas en la década anterior (Deux Marzi y Hintze, 2014, pág. 314).

La centralidad que adquiere el cooperativismo de trabajo y sus niveles de crecimiento evidencian la reivindicación del cooperativismo como alternativa para la superación de la crisis del empleo, que contrasta con los ritmos de menor evolución de otros tipos de cooperativas (Acosta et al., 2013, pág. 28).

De acuerdo con el análisis que realizan Acosta et al., (2013) este proceso da lugar a una reconfiguración del sector, que queda en evidencia si se considera que para el año 2001 las cooperativas de trabajo representaban el $42 \%$ del total de cooperativas activas y para el año 2012 ya alcanzaban el $72 \%$. Este cambio de composición se observa también si se tiene en cuenta que del total de cooperativas activas para el año 2012, el 93\% (lo cual representa 14.001 entidades) fueron matriculadas después del año 2003. En la actualidad, las cooperativas de trabajo representan el $78,6 \%$ de la totalidad de las cooperativas ${ }^{4}$.

Existe una coincidencia notoria entre autores/as (Vuotto, 2011, pág. 18; Acosta et al., 2013, pág. 36; Deux Marzi y Hintze, 2014, págs. 314-315) respecto a que la expansión de las cooperativas de trabajo que se manifiesta desde inicios del 2000 , responde por un lado a la institucionalización de nuevas formas asociativas como es el caso particular de las empresas recuperadas cuyos trabajadores las formalizan bajo la figura de cooperativa de trabajo. Por otro lado, responde también a la creación de nuevas cooperativas surgidas a partir del impulso de programas estatales que se orientan a la creación de empleo, el desarrollo local y la inclusión 3 De acuerdo con datos del "Reempadronamiento nacional y censo económico cooperativo y mutual" realizado por el Instituto Nacional de Asociativismo y Economía Social (INAES).

4 Consulta realizada en la página oficial del INAES el día 22 de junio de 2018. 
social de los sectores marginados por medio de la autogestión, y que contemplan al cooperativismo de trabajo como herramienta ${ }^{5}$.

En particular, Vuotto (2011, pág. 20) destaca que la modificación de la configuración del sector se da de manera sensible a partir del año 2003 cuando se constituyen las primeras cooperativas de trabajo en la provincia de Buenos Aires promocionadas desde el gobierno nacional mediante el Programa Federal de Emergencia Habitacional, el cual luego se amplía al resto de las provincias. La importancia de este tipo de cooperativas vinculadas a planes se observa en su representación en la composición del total de cooperativas de trabajo, ya que ascienden al $76 \%$ del total de cooperativas activas para el año 2012 (Acosta et al., 2013, pág. 36)

De acuerdo con información disponible en el Instituto Nacional de Asociativismo y Economía Social (INAES) ${ }^{6}$, se identifican 23.327 cooperativas de trabajo activas en Argentina. Se destacan las situaciones de algunas provincias como Buenos Aires y Tucumán, ocupando la provincia de Santa Fe el quinto lugar en términos de cantidad de cooperativas de trabajo matriculadas en la actualidad (1.105 cooperativas).

Tradicionalmente la provincia de Santa Fe ha sido una de las provincias argentinas donde más se ha propiciado la constitución y el desarrollo de mutuales y cooperativas, originadas en gran medida por la influencia de inmigrantes europeos que han poblado la zona agrícola-ganadera a lo largo de los siglos XIX y XX (Cardozo, Serafino, Soto y Tealdo, 2017, pág. 4).

A pesar de ser un territorio donde primó durante mucho tiempo el cooperativismo agropecuario, se observa desde hace unas décadas un claro predominio de las cooperativas de trabajo, proceso que remite a lo acontecido a nivel nacional. Este tipo de cooperativas constituyen en la actualidad, de acuerdo a los datos disponibles por INAES, el $67 \%$ del total del sector cooperativo en la provincia, seguido por las de servicios públicos que representan un $12 \%$ del total. Luego se ubican las cooperativas agropecuarias con una participación del $9 \%$, las de provisión con un $7,6 \%$, Construcción y vivienda con un $2,7 \%$, las de Consumo con un $0,97 \%$, y las de Crédito y Seguros con un $0,85 \%$ en conjunto.

\footnotetext{
5 Algunos trabajos recientes observan las transformaciones que se produjeron en las políticas públicas vinculadas a la promoción y fortalecimiento de la economía social en nuestro país, a partir del cambio de gestión del gobierno nacional en el año 2015 (Arcidiácono y Bermúdez, 2018; Hopp, 2018; Ferrari, Mango y Campana, 2018). En particular, Hopp (2018) destaca el "giro descooperativizador" que se da a partir de cambios normativos que implican la eliminación de la figura de las cooperativas como organizadora del trabajo - tal como se desarrollaba en el marco de los programas sociales- $y$ un nuevo énfasis colocado en la formación para la empleabilidad y la cultura del trabajo.

6 Consulta realizada en la página oficial del INAES el día 06 de junio de 2018.
} 
Tabla 1. Cantidad de Cooperativas, según tipo. Provincia y ciudad de Santa Fe, 2018.

\begin{tabular}{|l|c|c|}
\hline \multicolumn{1}{|c|}{ Cooperativas } & Provincia de Santa Fe & Ciudad de Santa Fe \\
\hline Trabajo & 1107 & 104 \\
\hline Agropecuaria & 146 & 1 \\
\hline Consumo & 16 & 0 \\
\hline Crédito & 11 & 0 \\
\hline De provisión & 126 & 11 \\
\hline Seguros & 3 & 0 \\
\hline Servicios públicos & 197 & 2 \\
\hline Vivienda y construcción & 45 & 6 \\
\hline TOTAL & $\mathbf{1 6 5 1}$ & $\mathbf{1 2 4}$ \\
\hline
\end{tabular}

Fuente: Elaboración propia en base a datos del INAES.

En la ciudad de Santa Fe, por su parte, según el INAES al año 2018 se encontraban registradas 124 cooperativas, de las cuales 104 eran de trabajo, y de ellas el $80 \%$ se matriculó luego del año 2001. Éstas representan en la ciudad el 83,9\% del total de cooperativas, seguidas por las cooperativas de provisión con un $8,9 \%$; un $4,8 \%$ las de vivienda y construcción, servicios públicos con $1,6 \%$ y el $0,8 \%$ las agropecuarias. De acuerdo con el análisis hasta aquí desarrollado de la evolución de cooperativismo de trabajo en Argentina, mediante el cual se identifican dos procesos que motorizan desde inicio del siglo XXI el impulso de las mismas, se pueden reconocer algunas particularidades para la ciudad de Santa Fe. La creación de cooperativas de trabajo a partir de la recuperación de empresas por sus trabajadores ha tenido un impacto marginal, siendo mayor el impacto de las políticas públicas tanto de nivel nacional, como local y provincial, en el surgimiento de estas organizaciones.

\section{Políticas públicas de fomento al sector}

A nivel nacional, los programas que mayor impacto han tenido en términos de creación de cooperativas de trabajo, bajo la órbita del Ministerio de Desarrollo Social de la Nación, han sido el Programa Manos a la $\mathrm{Obra}^{7}$, surgido en el año 2003, y desde el año 2009 los Centros Integradores Comunitarios ${ }^{8}$, el Programa de Inversión Social ${ }^{9}$ y el Programa de Ingreso Social con Trabajo (PRIST) ${ }^{10}$. Bajo la órbita del

7 Este programa tiene como objetivo la integración social de los sectores vulnerables a través del sistema productivo, mediante el fomento al desarrollo local y la economía social. Para ello contempla el financiamiento de experiencias productivas y/o comunitarias, y su asistencia técnica permanente. 8 Se contempla la construcción de dichos Centros Integrales Comunitarios por parte de cooperativas de trabajo.

9 Este programa contempla la realización de pequeña obra pública municipal provista por cooperativas de trabajo.

10 Se dirige a la promoción del desarrollo económico y la inclusión social, mediante la generación de puestos de trabajo genuinos por medio del impulso de organizaciones sociales de trabajadores (Resolución 3182/09). Para su implementación, el Ministerio de Desarrollo Social de la Nación acuerda con los Entes Ejecutores (municipios, provincias, federaciones o mutuales), por medio del INAES, la formación y capacitación de cooperativas compuestas por alrededor de 60 trabajadores/ 
Ministerio de Planificación Federal, Obras Públicas y Servicios de la Nación han sido relevantes los programas Agua+Trabajo y Cloacas+Trabajo ${ }^{11}$ (creados en el año 2004) y el Programa Federal de Integración Sociocomunitaria ${ }^{12}$ (del año 2008) (Acosta et al., 2013, pág. 36).

Sin embargo, el alcance de dichos programas nacionales ha sido muy limitado en la ciudad de Santa $\mathrm{Fe}$, identificándose en particular algunas cooperativas de trabajo surgidas de los programas del Ministerio de Planificación Federal, Obras Públicas y Servicios de la Nación, como el Programa Agua+Trabajo.

En este marco, las políticas locales y provinciales de fomento al sector han tenido un rol preponderante. A nivel provincial, las acciones de fomento al sector se enfocaron desde el año 2011 en la capacitación, asistencia técnica y financiamiento por medio de aportes no reintegrables, bajo la órbita de la Subsecretaría de Economía Social del Ministerio de Desarrollo Social de la Provincia de Santa Fe. En el año 2015, dichas acciones de promoción del cooperativismo de trabajo pasan a concentrarse en el Ministerio de Producción de la Provincia de Santa Fe, con la creación de la Secretaría de Desarrollo Territorial y Economía Social. En la actualidad, se puede identificar -entre otros- el Programa Crear Comunidad Emprendedora, que contempla el financiamiento a entidades cooperativas por medio de créditos, microcréditos y aportes no reintegrables, además de capacitación, asistencia técnica y acompañamiento para el desarrollo de sus idea-proyectos.

A nivel local, se destaca el Programa Iniciativa Comunitaria y Cooperativas de Trabajo (Ordenanza 10100/96 y modificatoria de Ordenanza 11672/10), el cual promueve la celebración de convenios entre el Municipio y cooperativas de trabajo para la realización de pequeñas obras y servicios mano de obra intensivos. En este marco se fomenta la creación de cooperativas, las cuales además deben inscribirse en un Registro de Cooperativas Proveedoras (Ordenanza 11672/10), y con ello se establece un régimen de prioridad para la contratación de trabajo, bienes o servicios, sumado a la responsabilidad por parte del Municipio de brindarles asistencia jurídica y contable, monitoreo permanente, capacitación empresarial y técnico-profesional.

Al año 2013, el gobierno local ya contaba con 45 convenios con asociaciones civiles y cooperativas de trabajo para realizar trabajos de mantenimiento y limpieza en espacios públicos, desobstrucción de desagües a cielo abierto, obras de extensión de agua y red cloacal, producción de canalones y construcción de módulos habitacionales (Municipalidad de Santa Fe, 2013).

Estas y otras acciones acompañaron -aunque con diversos resultados- un sector de fuerte crecimiento en la ciudad y la región durante las últimas décadas, sector que

as cada una, quienes tienen a su cargo la ejecución de obras públicas locales que demandan mano de obra intensiva (Acosta et al., 2013, pág. 36).

11 Promueven la constitución de cooperativas de trabajo de saneamiento, y con ello la extensión de los servicios básicos de agua potable y desagües cloacales.

12 Promueve la incorporación de mano de obra fundamentalmente proveniente de personas desocupadas que conformen cooperativas de trabajo, para contribuir al desarrollo y mejoramiento de las condiciones de hábitat, vivienda, infraestructura básica y equipamiento comunitario de hogares con NBI y grupos vulnerables en situación de emergencia (Resolución 1270/08). 
sin embargo vio la necesidad de constituir organizaciones de apoyo que promuevan el fortalecimiento de las cooperativas que las componen y, con ello, de todo el sector cooperativo.

\section{Mecanismos de integración cooperativa: objetivos, sentidos y efectos.}

Las posibilidades de integración y coordinación forman parte de los principios cooperativistas de actual vigencia, establecidos por la Alianza Cooperativa Internacional $(\mathrm{ACl})$ en su II Asamblea General en el año 1995, los cuales integran explícitamente el de "cooperación entre cooperativas". El mismo hace referencia a que las cooperativas servirán más eficazmente a sus miembros y fortalecerán el movimiento cooperativo mediante el trabajo conjunto por medio de estructuras locales, nacionales, regionales e internacionales. De este principio se deriva que una cooperativa deberá colaborar con otras y estar dispuesta a asociarse con ellas en el plano de unos intereses comunes (Alfonso Alemán, Rivera Rodríguez y Beltré Jiménez, 2014, pág. 7).

La incorporación de dicho principio en la normativa argentina establece las posibilidades de integración mediante herramientas concretas. La Ley de Cooperativas 20.337 prevé la integración cooperativa como uno de los caracteres esenciales de las mismas (Art. 2, inciso 9) y contempla específicamente en el capítulo IX las diversas formas de integración posibles. Althaus (1983, pág. 15) destaca que la ley es amplia en esta materia dada las diversas posibilidades que brinda y modalidades, destacando algunas más intensas y otras más débiles.

Las posibilidades entonces varían desde la simple asociación entre cooperativas para el mejor cumplimiento de sus fines (Art. 82) o con personas de otro carácter jurídico (Art. 5), en tanto sea conveniente para su objeto social y no desvirtúe su propósito. Así mismo, existe la posibilidad de la fusión o incorporación (Art. 83) y hasta la de convenir entre cooperativas realizar una o más operaciones en común (Art. 84).

La integración mediante cooperativas de grado superior, de particular interés para este análisis, se regula en el Art. 85. Estas organizaciones pueden constituirse para el cumplimiento de objetivos económicos, culturales o sociales, y las mismas se rigen por las mismas disposiciones que las cooperativas y aquellas que resultan de su naturaleza. En su estatuto se debe establecer el régimen de representación y voto, de manera tal que "aseguren la participación de todas las asociadas e impidan el predominio excluyente de alguna de ellas" (Art. 85). Así mismo, las cooperativas que se integran lo hacen mediante resolución de su propia asamblea o del consejo de administración ad-referendum de ella.

Los motivos de constitución de cooperativas de grado superior pueden ser múltiples, pero una de las razones que lleva a las cooperativas a iniciar procesos de esta índole refiere a las posibilidades de crecimiento y fortalecimiento para cumplir con su objeto. Así Puentes (2004, citado en Alfonso Alemán et al., 2014, pág. 6) sintetiza razones económicas y sociales. En ese sentido, se puede considerar que los mecanismos de integración cooperativa como instancia de coordinación intersectorial se vinculan de alguna manera a objetivos de fortalecimiento del sector. Sin embargo, se reconoce que de acuerdo a los tipos de cooperativas y al sector de la actividad económica 
al que las mismas pertenezcan, los desafíos y objetivos de una organización de segundo grado variarán.

Vuotto (2011), por su parte, destaca en la inter-cooperación la posibilidad de coordinar acciones y mutualizar ciertas funciones, a la vez que se respeta la autonomía estratégica y de desarrollo de cada uno de sus miembros. La confianza generada entre los diversos actores, por lo tanto, así como los niveles de colaboración, resulta un componente fundamental para lograr el éxito de dicha cooperación. De este modo, afirma que "la eficacia en el comportamiento de las entidades integradas está vinculada entre otros con el grado de compromiso de los miembros que integran la entidad" (pág. 24).

En ese sentido, también se puede reconocer que los procesos de intercooperación pueden generar efectos beneficiosos en la generación de capital social sobre la comunidad en la que se insertan las cooperativas. Putnam (1995) define al capital social como "las características de la organización social tales como las redes, las normas y la confianza que facilitan la coordinación y la cooperación para el beneficio mutuo" (pág. 66), el cual a su vez permite el logro de objetivos que no podrían alcanzarse en su ausencia, o que se haría a un costo mayor (Coleman, 1990, pág. 304).

Ciertos estudios demuestran que las características intrínsecas de las cooperativas favorece que sus miembros, y las organizaciones en sí, establezcan lazos y alianzas con otras redes sociales (Borzaga y Sforzi, 2014, citado en Bretos, Díaz-Fonceca y Marcuello, 2018, pág. 6), como lo son las relaciones intercooperativas.

\section{Federaciones de cooperativas de trabajo: antecedentes a nivel nacional y provincial}

A nivel nacional, la primera organización de segundo grado en el sector del cooperativismo de trabajo se constituye en el año 1954, con la Asociación de Cooperativas de Trabajo (ACTRA), conformada por cooperativas de transporte, estibaje, asistencia médica, industria textil, mecánica, gráfica y de la alimentación (Drimer y Drimer, 1973, citado en Vuotto, 2011, pág. 25). En la década de 1980 surgieron otras federaciones de mayor visibilidad en la provincia de Buenos Aires, como la Federación de Cooperativas de Trabajo (FECOOTRA), conformada en la actualidad por 53 cooperativas de trabajo, y la Federación de Cooperativas de Trabajo de Actividades Portuarias Navales y Afines (FECOOAPORT), integrada por 16 cooperativas de trabajo de estibaje.

A partir del año 2000, junto al impulso que cobra el cooperativismo de trabajo en nuestro país, también se produce un gran incremento de las organizaciones de segundo orden que nuclean a dichas cooperativas. Entre ellas, se crea en el año 2006 la Federación de Cooperativas de Trabajadores Autogestionados (FACTA), conformada en su gran mayoría por empresas recuperadas por sus trabajadores bajo la forma de cooperativa (Vuotto, 2011, pág. 25), seguida de la conformación, en el año 2009, de la Confederación Nacional de Cooperativas de Trabajo (CNCT). Esta organización de tercer grado se integra por 25 federaciones (que en la actualidad superan las 36 ), las cuales representan a 3.000 cooperativas y casi 30.000 trabajadores en todo el país (Vuotto, 2011, pág. 25). 
En el caso de la provincia de Santa Fe, actualmente cuentan con matrícula vigente del INAES seis federaciones de cooperativas de trabajo, nacidas todas al calor de las transformaciones económico-sociales antes mencionadas y el consiguiente incremento de las cooperativas de trabajo.

La primera de ellas, la Federación de Cooperativas de Trabajo de Rosario (FECOTRAR Ltda.), nace en el año 1999 en el sur provincial, conformada en gran parte por cooperativas del rubro de la construcción y afines. Diez años más tarde, en el norte de la provincia, se conforma la Federación de Cooperativas de Trabajo de Reconquista Ltda., también integrada por cooperativas dedicadas principalmente al rubro de la construcción. Ambas se encuentran actualmente nucleadas a nivel nacional a la CNCT.

En los años siguientes se conforman otras cuatro federaciones, en el centro y sur provincial.

Cabe destacar, a partir de la información disponible, que de las seis federaciones tres de ellas se ubican en el sector de la construcción y también son tres las que se han constituido formalmente en los últimos dos años. Esto da cuenta de las particularidades que los procesos de constitución de organizaciones de segundo nivel tienen en el territorio de la provincia de Santa Fe, el que no se puede aislar del contexto actual del cooperativismo de trabajo ${ }^{13}$.

A los fines de ahondar en el análisis, a continuación se describe el proceso de conformación del caso de estudio propuesto.

\subsection{Los orígenes, objetivos y motivaciones de la federación}

Existe una coincidencia notoria entre los entrevistados en torno al rol y motivos de constitución de la federación. La idea de la representación, como institución de segundo grado que nuclea a las cooperativas asociadas, se vincula a la posibilidad de tener un portavoz en el diálogo con referentes del Estado (u otros) y un rol político-gremial. Asimismo se asocia dicha representación al poder que consideran que acumulan mediante esta integración.

La importancia es la preponderancia que nos da como institución madre de las cooperativas, como para poder presentarnos a hablar en conjunto ante organismos. No es lo mismo que vaya una cooperativa sola a hablar que vaya un conjunto de cooperativas a través de una matrícula jurídica otorgada por el gobierno, ya es otro nivel (Entrevistado 3, comunicación personal, 5 de junio de 2017).

Los integrantes destacan la necesidad de unirse con el objeto de tener más fuerza al momento de realizar reclamos y pedidos, y la posibilidad que abre esta organización para gestionar recursos ante organismos estatales, de modo de fortalecer a las cooperativas miembros y con ello a todo el sector cooperativo. Además, conociendo la realidad de las dos federaciones de la provincia que ya funcionaban desde hacía 13 Vinculado a este proceso podemos destacar el apoyo y promoción al movimiento intercooperativo por parte del gobierno provincial, particularmente a partir de la incorporación en el año 2016 de las cooperativas de trabajo al Consejo Provincial de Asociativismo y Economía Social. Dicho Consejo se crea en el año 2012 como un espacio de diálogo entre el gobierno provincial y diversas entidades del sector, y con la misión principal de constituirse en órgano de consulta en materia cooperativa y mutual. 
muchos años, surge como necesidad contar con un órgano de representación que permita a su vez mejorar la comunicación entre las cooperativas:

El ideal de la Federación es tratar de poder posibilitar y gestionar recursos para las cooperativas que conforman la federación. Más allá de eso creo que todos tenemos la solidaridad de poder pelear por las otras cooperativas, pero principalmente el objetivo de la Federación es gestionar y potenciar las cooperativas (Entrevistado 3, 2017).

(la federación surge) para tener más fuerzas para pedir cosas al gobierno también. No sé hacer piquetes ni nada, yo no soy así, no quiero joderle la vida a nadie; pero sí tener fuerza para presentar notas y eso (Entrevistado 1, comunicación personal, 1 de Junio de 2017).

Esa idea de organización de nivel superior que tiene como objetivo pelear, negociar y conseguir mejoras en diversos aspectos para el conjunto de cooperativas, se puede traducir en términos más concretos en el avance en los derechos de los trabajadores, mejora en beneficios (como seguros, cobertura de salud, etc.) y convertir la federación en un canal de articulación de posibles programas estatales.

Es importante reconocer en ese sentido el contexto en donde surge esta federación. De las diez cooperativas que la integran, la mayoría se dedican al rubro de la construcción y presentan fuertes vínculos con el Estado -principalmente local-, siendo para algunas de ellas el principal demandante de sus servicios. Algunas de estas cooperativas incluso surgen de programas de promoción al sector, como el Programa Agua+Trabajo del Ministerio de Planificación Federal, Inversión Pública y Servicios de la Nación. Otras se dedican a la prestación de servicios públicos, el reciclado y el servicio de mantenimiento. A su vez, la mayor parte de ellas se encuentran localizadas en la zona norte y oeste, particularmente en barrios periféricos de la ciudad, y sus asociados ven en estas organizaciones una forma de inserción laboral ante un contexto de creciente desempleo y vulnerabilidad. En ese sentido, las posibilidades que brindan las cooperativas de acceso al trabajo no están exentas de dificultades, las cuales se ponen de manifiesto en las condiciones en que este se desarrolla.

Y una parte de una forma de trabajo encubierto es la cooperativa, y que si bien gracias a Dios es una de las formas que salgan pero ni siquiera te dignifica, digamos te tenés que dignificar con ya te digo con ropa, que esté bien remunerado los sueldos, porque cada vez hay más gente excluida (...) por ahí lamentablemente te están pidiendo trabajo tres, cuatro pibes por día (Entrevistado 3, 2017).

Acá y alrededor hay muchísimas cooperativas de trabajo, algunas que han trabajado, otras que lo buscan, que como nosotros sale a buscar...esto es para generar fuente de trabajo, para no quedarnos sin trabajo y sacar a los chicos de la calle. Eso es lo que yo hago. Copa de leche, talleres de herrería, centro de atención en adicciones (Entrevistado 1, 2017).

Reconocen en este contexto las dificultades que se presentan para el sector, dentro de ellas principalmente el poder conseguir trabajo y sostener la cooperativa y sus miembros. Frente a esto es recurrente, por un lado, el reclamo a los distintos niveles de gobierno para que generen condiciones de trabajo que puedan ser aprovechadas 
por las cooperativas. Algunos de los entrevistados remarcan la necesidad de que se reconozca su derecho a trabajar y se gestione desde el sector público los medios necesarios para tal fin. Sin embargo, dos de los entrevistados reconocen una situación de dependencia de estas cooperativas para con el Estado.

Por otra parte, muchas de las acciones propuestas por la Federación se dirigen específicamente al sector de la construcción, reconociendo de esta manera la actividad principal que realizan muchas de las cooperativas que la integran, las cuales representan cerca del $70 \%$ del total.

\subsection{El proceso de conformación. Actores, vínculos y tensiones}

El proceso de conformación de esta federación estuvo también atravesado por marchas y contramarchas, que entendemos propio de un proceso de integración en un sector con heterogeneidades y diversidad de posiciones entre sus actores.

Una de las dificultades iniciales fue sumar la cantidad de cooperativas necesarias para constituir la federación, pero luego el desafío pasó por mantener una representación que sea justa para todos los integrantes, de modo que cada persona participe en nombre de una sola cooperativa.

Sumado a ello, y como parte de una dificultad que se ubica en al ámbito de las cooperativas de trabajo en general, las cuestiones administrativas fueron un elemento que debieron atender y resolver específicamente: a la documentación propia de la federación, se sumó la necesidad de que todas las cooperativas que la conforman se encuentren debidamente registradas ante los organismos correspondientes. Se observa que este aspecto en particular se cubre principalmente desde un área de asesoría externa de la federación, debido a los conocimientos técnicos necesarios en la materia, lo que permite que finalmente estas cooperativas puedan integrarse a la conformación inicial de la organización.

Entonces en 2014 se quiso armar, pero estaba el tema de convocar a las cooperativas y además nadie sabía para qué conformar una federación. Hasta que se consiguieron diez cooperativas, se hizo el Estatuto (...) Entonces después se mandó al INAES, pero había cooperativas que nunca habían mandado un papel al INAES. La mayoría eran cooperativas nuevitas (...) (constituidas) para trabajar con la municipalidad, no de manera exclusiva, pero era una herramienta más de trabajo (Entrevistado 2, comunación personal, 5 de Junio de 2017).

Este proceso así mismo se vio atravesado por tensiones entre actores, que pusieron de relieve disputas políticas y formas de trabajo diferentes. Como consecuencia de estas divergencias, algunos de quienes comenzaron participando de este proceso se retiraron por un tiempo, para finalmente integrarse a la federación antes de su inscripción, según lo manifiesta uno de los entrevistados. Si bien esto alertó a algunos de los miembros, todos reconocieron la necesidad en ese momento de conseguir la matriculación integrando a todas las cooperativas y luego continuar trabajando internamente en las cuestiones grupales.

Estas tensiones marcaron todo el proceso de conformación de la federación, donde finalmente primó el deseo de construir un espacio conjunto o, en términos de Putnam (1993) "un sentido de responsabilidad compartida para los esfuerzos colectivos" (págs. 89-90), propio de las organizaciones asociativas. 
Las prácticas de participación que caracterizan a las cooperativas -como la transparencia, la comunicación, la formación o la involucración en la toma de decisiones diarias-, resultan también necesarias en estas organizaciones de grado superior para que sus integrantes actúen y se relacionen de manera diferente, lo cual a su vez propicia la generación de capital social (Bretos et. al., 2018, pág. 8).

En términos de vínculos con otras instituciones y actores del sector, se destaca por un lado la Confederación Nacional de Cooperativas de Trabajo (CNCT), a la cual se adhieren reconociendo el vínculo institucional, pero luego de debates internos debido a diferentes posturas políticas. La decisión de adherirse a este espacio tiene como objeto el poder acceder a ciertos recursos que se manejan desde la coordinación nacional, además de la vinculación con otras cooperativas y actores del sector. Implica para los entrevistados una apertura hacia nuevas oportunidades que beneficiarán a las cooperativas que integran, aunque también mencionan que por el momento no han recibido ninguno de esos beneficios.

Con respecto a la relación que mantienen con el sector público, se observa una situación similar a la antes descripta: la adopción de una postura de apertura al diálogo y de generar cualquier tipo de vínculo que beneficie a la organización y a las cooperativas que la conforman. Sin embargo, se puede reconocer que algunos de los integrantes tienen diversas posturas y vínculos con diferentes actores institucionales que buscan aprovechar para el trabajo de la federación.

Algunos entrevistados identifican que la generación de estos vínculos aún se torna difícil ya que necesitan consolidarse como organización y madurar el proceso iniciado como federación. En términos de Mugarra (2005) se podría considerar que es necesario avanzar en el fortalecimiento del capital social "de aproximación", aquel que surge de las redes de relaciones con otros grupos o comunidades similares (en este caso, las otras cooperativas). Así mismo la federación genera, a partir de los vínculos con otras organizaciones de nivel superior y con el propio Estado, capital social "de vinculación" mediante las relaciones establecidas con otros grupos o redes externas y que surgen debido al compromiso con el entorno y las necesidades de la sociedad que presentan dichas organizaciones ${ }^{14}$.

\subsection{Una mirada acerca del rol de la federación. Potencialidades y desafíos}

Tal como ya fuera mencionado, la reciente federación se encuentra en un proceso de iniciación y encontrando su dinámica de funcionamiento interna. En ese sentido, se pretende en este apartado identificar aquellas acciones en las que se encuentran trabajando y los desafíos aún pendientes.

Si bien se reconoce que es aún limitado el nivel de trabajo conjunto en proyectos concretos, el proceso de construcción de este espacio de integración viene gestando una dinámica propia que pueda contener todas las demandas e intereses de las cooperativas, con el desafío de generar consensos y de sortear las diferencias.

Los espacios de discusión y reuniones internas parecieran no ser sistemáticos. Por un lado, se pudo reconocer que la limitante de tiempo de sus integrantes es

14 Mugarra (2005) también desarrolla el capital social de "unión", como aquellas redes de relaciones generadas al interior de un grupo o comunidad. 
un elemento que dificulta la participación, pero así mismo algunos entrevistados reconocen la necesidad de dedicación que este tipo de integración requiere. Del mismo modo, las reuniones se plantean como el espacio para proponer acciones y reconocer las demandas de las cooperativas, pero están vinculadas al tratamiento de temas específicos, por ejemplo como espacio de encuentro con instituciones o agentes externos. Se observa así diferentes niveles de participación y compromiso por parte de las cooperativas que la componen, lo que se puede asociar de algún modo a los roles institucionales que se asumen.

Entre las principales acciones desarrolladas hasta el momento, y de la mano de uno de los reclamos principales de sus integrantes sobre la recepción de ayudas económicas, se inició la gestión de programas vinculados al sector, mediante el diálogo con el INAES. En ese marco se realizó un viaje conjunto hasta Buenos Aires para plantear las necesidades y la posibilidad de articular a través de la federación dichos programas; sin embargo de acuerdo a los tipos de demandas (maquinarias, herramientas de construcción, etc.) la solicitud de los apoyos se comenzó a gestionar individualmente por cooperativa. También se encuentran en diálogo con las dependencias afines de los restantes niveles del Estado, pero nuevamente las gestiones concretas se dan a nivel individual.

En el mismo sentido, los vínculos con la CNCT han posibilitado la asistencia de alguno de los participantes de la federación a encuentros donde ha primado el intercambio con otras cooperativas y organizaciones de segundo grado, y discusiones sobre el sector.

Estas ideas iniciales acerca del funcionamiento de la federación, por otra parte, plantean algunos desafíos puntuales, según los propios participantes han podido manifestar.

El fortalecimiento de la federación como herramienta colectiva que debe sostenerse y partir del compromiso de todos los integrantes, de modo que se pueda avanzar efectivamente en gestiones, demandas y proyectos para todas las cooperativas es una idea mayormente compartida. También se destaca la necesidad de sostener el trabajo realizado hasta el momento, sobreponiéndose a cualquier diferencia.

Así mismo, la sumatoria de más cooperativas que puedan integrarse a la federación se visualiza como doble necesidad, no sólo por el hecho de formar parte de la organización sino también para acompañar dicha posibilidad colaborando y asistiendo en el tema administrativo. Nuevamente, las dificultades de regularización de las cooperativas emergen como un obstáculo persistente.

La necesidad de avanzar en términos de acción mediante proyectos concretos es primordial para muchos de los entrevistados. De los reclamos y gestiones más importantes que se pudieron recabar surge el mejoramiento de las condiciones de trabajo en cuanto a los niveles de pago, condiciones de los convenios suscriptos con las dependencias estatales y el acceso a derechos vinculados al trabajo. En ese sentido, se destacan la necesidad de valorar el trabajo cooperativo y reconocer el trabajo que muchas veces estas organizaciones realizan, más allá de sus competencias específicas. También se evidencia que la provisión de servicios (de obra social, crédito, seguros, etc.) es un aspecto interesante para las funciones de 
la federación.

Pero en estos momentos y como te hacen trabajar no podés hacer nada porque es totalmente... la federación tiene que ser medio para gestionar baños químicos, la ropa, y todo eso que no te entregan, por el tema de trabajo por convenio (Entrevistado 3, 2017).

(...) que podamos luchar para tener más cosas. Que podamos obligar al gobierno, el que sea, que nos dé nuestros derechos (Entrevistado 1, 2017).

Finalmente, la idea específica de fortalecimiento del movimiento no emerge de modo explícito, como tampoco el desarrollo o fortalecimiento de vínculos con el entorno local. Reconociendo la capacidad diferencial que poseen las cooperativas y organizaciones intercooperativas para generar capital social de aproximación en sus territorios, por medio de la creación de redes sociales sólidas y duraderas con proveedores y clientes locales (Bauer, Guzmán y Santos, 2012), así como con otras cooperativas y organizaciones sociales (Birchall, 2010, citado en Bretos et. al., 2018, pág. 9), resulta una posibilidad aún limitada y a continuar explorando para esta organización. En ese sentido, se entiende que las demandas más urgentes trazan el camino a recorrer.

\section{Reflexiones finales}

El análisis del proceso de creación de la federación permite pensar la complejidad intrínseca de las experiencias de trabajo asociativo mercantil y de la integración intercooperativa en el desarrollo de objetivos comunes.

Inicialmente, se debe destacar el rol de representación que los integrantes atribuyen y comparten respecto a las motivaciones de constitución de la organización de segundo grado, entendiendo el mayor poder de negociación que esta herramienta les permite. Pero este rol pareciera tener una orientación, al menos inicial, bastante clara en relación a las características particulares que la federación presenta.

En primer lugar, se reconoce que las cooperativas que la conforman son organizaciones que surgen en barrios de la periferia de la ciudad, atravesados por situaciones de vulnerabilidad y desempleo, y que a su vez se encuentran vinculadas en gran medida a políticas públicas de promoción del empleo, sobre todo en el sector de la construcción. En este sentido, resulta llamativo la fuerte orientación que tienen las competencias de la federación hacia este rubro, lo que podría dar cuenta de ciertos límites respecto a las cooperativas de trabajo en general.

En segundo lugar, y de la mano de lo anterior, las demandas que claramente están atravesando la federación refieren a las mejoras en términos de calidad y derechos del trabajo. Respecto a esto es interesante observar de qué manera el vínculo con el Estado se vuelve central, debido a la dependencia que en términos laborales y de asistencia existe en algunos casos, pero también como uno de los principales agentes receptores de las demandas y reclamos.

En el caso analizado, por otra parte, las diferencias internas tienen lugar desde los inicios de la conformación, producto de miradas y posturas políticas disímiles. Resulta difícil, en primer término, hacer confluir estas diversas visiones, pero al mismo tiempo lograr un compromiso real de cada uno de los integrantes en términos de participación y sostenimiento de la federación. 
Se debe destacar, en este sentido, que una de las características distintivas de este tipo de organizaciones, como fue desarrollado, es la de generar capital social. Algunos autores mencionan que las cooperativas (como las organizaciones intercooperativas), generan capital social al favorecer el establecimiento de vínculos estables de cooperación con proveedores y clientes locales (Bauer et al., 2012), por medio de la creación de confianza entre sus miembros (Sabatini, Modena y Tortia, 2014), o mediante la generación de interdependencia y reciprocidad entre ellos, un sentimiento de pertenencia y confianza mutua, además de la cooperación o el fortalecimiento de las redes sociales (Bretos et. al., 2018, pág. 16). En el caso aquí descripto, si bien se trata de una organización de reciente constitución, estas características se observan difusas y con ciertas dificultades. Encontrar equilibrios que permitan la construcción de vínculos de confianza es parte de los desafíos de todo proceso colectivo y conlleva la necesidad de generar consensos. No se desconoce, sin embargo, la desarticulación generalizada de la economía popular en Argentina.

Tal como plantea Coraggio (2013), estos procesos están fundados en equilibrios de poder y negociaciones coyunturales dentro de los mismos movimientos. En este sentido, dichos movimientos también se encuentran atravesados por contradicciones internas, por lo que se constituye en un desafío "defender la vigencia del mandato político a la vez que comienzan a adecuar las prácticas económicas a las nuevas propuestas de institucionalización" (Coraggio, 2013, pág. 17).

Se cree que estas características deben comprenderse, así mismo, como parte de la etapa inicial de un proceso en permanente construcción, que como alguno de sus integrantes reconoce se relaciona a la maduración que aún debe decantar y que se encuentra signado por la necesidad de resolver algunas problemáticas más urgentes de las propias cooperativas (en términos materiales y de acceso al trabajo), resultando la federación un instrumento mediador para lograr dicho objetivo.

Ante esta situación, surge el interrogante acerca de cómo se piensa el rol de dicha organización en un contexto más amplio y cuáles son sus reales posibilidades y potencialidades para el fortalecimiento del sector cooperativo de trabajo. Si bien se reconoce como acciones posibles de la federación la provisión de servicios tales como obra social, créditos, seguros, etc., esto no es visto como un objetivo a corto plazo, ni tampoco como una de las principales necesidades del sector. Sin embargo, la creación de una herramienta colectiva para el fortalecimiento de las cooperativas de trabajo a partir de la institucionalización de una federación con la que antes no se contaba a nivel local, resulta en sí mismo un hecho de movilización.

\section{Referencias bibliográficas}

Acosta, M. C., Levin, A. y Verbeke, G. E. (2013). El sector cooperativo en Argentina en la última década. Cooperativismo \& Desarrollo, 21(102), 27-39

Alfonso Alemán, J. L., Rivera Rodríguez, C. A. y Beltré Jiménez, T. (2014). Cooperativas de segundo grado. Una necesidad para el desarrollo del cooperativismo agropecuario en la República Dominicana. Revista Cooperativismo \& Desarrollo, 3(1). 
Althaus A. (1983) El régimen jurídico de las organizaciones cooperativas en la República Argentina. Revista de Idelcoop, 10(36).

Arcidiácono, P. y Bermúdez, A. (2018). ¿Cooperativismo como oportunidad perdida? Problemas estructurales y coyunturales del cooperativismo bajo programas. Ciudadanías. Revista de Políticas Sociales Urbanas, 2, 83-111.

Bauer, C. M., Guzmán, C. y Santos, F. J. (2012). Social capital as a distinctive feature of Social Economy firms. International Entrepreneurship and Management Journal, 8, 437-448.

Bretos, I.; Díaz-Fonceca, M.; Marcuello, C. y Marcuello, C. (2018). Cooperativas, capital social y emprendimiento: Una perspectiva teórica. REVESCO. Revista de Estudios Cooperativos, (128).

Cardozo, L. G.; Serafino, E.; Sotto, O. y Tealdo, J. (2017). Mapeo de la Economía Social y Solidaria en el municipio de Santa Fe (Argentina): creación de una base de datos actualizada de las diferentes experiencias. Cooperativismo \& Desarrollo, 25(110).

Chaves, R. (1999). La Economía Social como enfoque metodológico, como objeto de estudio y como disciplina científica. Revista CIRIEC-España, 33, 115-140.

Coleman, J. S. (1990). Foundations of Social Theory. Cambridge, Inglaterra: Harvard University Press.

Coraggio, J. L. (2013). La Presencia de la Economía Social y Solidaria (ESS) y su Institucionalización en América Latina. En Conferencia UNRISD "Potential and Limits of Social and Solidarity Economy". Conferencia realizada en Geneva, Suiza.

Coraggio, J. L. (2011). Economía Social y Solidaria. El trabajo antes que el capital. Quito, Ecuador: Abya-Yala.

Defourny, J. (2009). Economía Social. En D. Cattani, J.L. Coraggio y J-L Laville. (Org.) Diccionario de la otra economía. Buenos Aires, Argentina: Universidad Nacional de General Sarmiento, Altamira, CLACSO.

Defourny, J. y Develtere, P. (2001). Orígenes y contornos de la economía social en el Norte y en el Sur. En J. Defourny, P. Develtere y B. Fonteneau. (Eds.). La Economía Social en el Norte y en el Sur. Buenos Aires, Argentina: Corregidor.

Deux Marzi, M. V. y Hintze, S. (2014). Protección y seguridad social de los trabajadores asociativos autogestionados. En C. Danani y S. Hintze. (Coords.). Protecciones y desprotecciones (II): problemas y debates de la seguridad social en la Argentina (311-362). Buenos Aires, Argentina: UNGS.

Ferrari Mango C. y Campana J. (2018). Del "Argentina Trabaja - Programa Ingreso Social con Trabajo" y el "Ellas Hacen" al "Hacemos Futuro". ¿Integralidad o desintegración de la función social del Estado? Observatorio sobre Políticas Públicas y Reforma Estructural - FLACSO Argentina. Informe $N^{\circ} 11$. 
Hintze, S. (2007). Políticas sociales argentinas en el cambio de siglo. Conjeturas sobre lo posible. Buenos Aires, Argentina: Espacio Editorial.

Hopp, M. (2018). Sostenibilidad y promoción del trabajo asociativo, cooperativo y autogestionado en la Argentina actual. Otra Economía, 11(20), 156-173.

Mugarra, A. (2005). Capital social y cooperativas: la experiencia del País Vasco. Ekonomiaz, 59, 306-329.

Municipalidad de Santa Fe. (2013). Cooperativas de Trabajo: una oportunidad de empleo y capacitación. Municipalidad de Santa Fe. Recuperado de http:// santafeciudad.gov.ar/noticia/cooperativas_trabajo_oportunidad_empleo_ capacitacion

Pastore, R. (2008). Diversidad de trayectorias, aproximación conceptual y pluralidad de proyectos de la Economía Social. Documento del Centro de Estudios de Sociología del Trabajo. Buenos Aires, Argentina: Facultad de Ciencias Económicas, Universidad de Buenos Aires.

Putnam, R.D. (1995). Bowling Alone: America's Declining Social Capital. Journal of Democracy, VI, 65-78.

Putnam, R.D. (1993). Making democracy work. Princeton, NJ: Princeton University Press.

Sabatini, F., Modena, F. y Tortia, E. (2014). Do cooperative enterprises create social trust? Small Business Economics, 42, 621-64.

Vuotto, M. (2011). El cooperativismo de trabajo en Argentina. Contribuciones para el diálogo social. Buenos Aires, Argentina: Oficina Internacional del Trabajo.

\section{Leyes, Decretos, Resoluciones y Ordenanzas}

Consejo Municipal de la Ciudad de Santa Fe. (1996). Ordenanza Municipal 10100. Recuperado de http://www.concejosantafe.gov.ar/Legislacion/ordenanzas/ ORDE_10100.pdf

Consejo Municipal de la Ciudad de Santa Fe. (2010). Ordenanza Municipal 11672/10. Recuperado de www.concejosantafe.gov.ar/Legislacion/ ordenanzas/ordenanza $\% 2011672 \% 20$ modificaci $\%$ C3\%B3n $\% 20$ del $\% 20$ art\%C3\%ADculo\%203\%20de\%20la\%20ordenanza\%2010100.pdf

Gobierno de la Provincia de Santa Fe. (2012). Decreto Provincial 3059: Crea el registro de bienes y servicios ofrecidos por las cooperativas de trabajo en el Ministerio de Desarrollo Social. Recuperado de www.santafe.gov.ar/index. php/web/content/view/full/196167/(subtema)/192166

Legislatura de la Provincia de Santa Fe. (2004). Ley Provincial 12375: Programa de Promoción y Asistencia a Emprendimientos Productivos Sociales. Recuperado de www.santafe.gov.ar/index.php/web/Estructura-de-Gobierno/ 
Ministerios/Produccion/Normas/Ley-Provincial-12375-Programa-dePromocion-y-Asistencia-a-Emprendimientos-Productivos-Sociales

Ministerio de Desarrollo Social de la Nación. (2009). Resolución 3182: Creación del "Programa de Ingreso Social con Trabajo". Recuperado de http://digesto. desarrollosocial.gob.ar/normaTexto.php?ld=247\&organismo=Ministerio\%20 de\%20Desarrollo\%20Social

PresidenciadelaNaciónArgentina.(1973).LeydeCooperativas20337. Recuperadode: http://servicios.infoleg.gob.ar/infolegInternet/anexos/15000-19999/18462/ texact.htm

Secretaría de Obras Públicas dependiente del Ministerio de Planificación Federal, Inversión Pública y Servicio (2008). Resolución 1270: Creación del “Programa Federal de Integración Sociocomunitario".

\section{Otras Fuentes de información consultadas}

Confederación Nacional de Cooperativas de Trabajo: http://www.cnct.org.ar/

Cooperativas de las Américas: http://www.aciamericas.coop

Instituto Nacional de Asociativismo y Economía Social: http://www.inaes.gob.ar Municipalidad de Santa Fe: http://www.santafeciudad.gov.ar 